\title{
Percepção de estudantes concluintes do curso de Administração sobre planejamento da carreira: vou estudar maquiagem cinematográfica na Califórnia
}

\section{Graduating students perception of the Administration course on planning career: I will study film makeup in California}

\author{
SERGIO RICARDO SIANI* \\ YEDA CIRERA OSVALDO** \\ DALILA ALVES CORR $\hat{E} A^{* * *}$
}

\section{RESUMO}

A carreira profissional é um assunto que ganhou maior interesse a partir da Revolução Industrial, passou por períodos de grande crescimento da atividade produtiva das empresas, sofreu impactos dos avanços das relações de trabalho e também da desconfiguração do modelo tradicional de sucesso profissional. Trata-se de uma temática de interesse dos pesquisadores dadas as diferentes configurações que a gestão das empresas vem assumindo ao longo do tempo e das transformações dos ciclos econômicos. Nesse cenário, o presente estudo abordou o planejamento da carreira entre jovens em fase de conclusão do curso universitário. O objetivo foi investigar as considerações que esse público associa à carreira e como percebem o seu planejamento. Trata-se de um estudo qualitativo, exploratório, desenvolvido com 42 estudantes concluintes do curso de Administração de

* Universidade Metodista de Piracicaba - UNIMEP. Programa de Pós Graduação em Administração - PPGA. Curso Mestrado Profissional em Administração. sergiosiani@gmail.com

*** Universidade Metodista de Piracicaba - UNIMEP. PPGA - Mestrado Profissional de Administração - UNIMEP. Mestrado Profissional de Administração - PPGA - UNIMEP. yedaconsult@terra.com.br

**** Universidade Metodista de Piracicaba - UNIMEP. PPGA - Curso doutorado em Administração - UNIMEP. PPGA - Universidade Metodista de Piracicaba. dacorrea@unimep.br 
uma instituição de ensino superior privada. Por meio do uso de entrevistas, questionários e anotações de salas de aula, os dados foram levantados em dois períodos distintos (2015 e 2016). Os principais resultados mostram que a carreira profissional é função das concepções que os estudantes associam ao trabalho, a seus projetos de vida e ao sucesso profissional. Tais aspectos influenciam diretamente o planejamento da carreira.

Palavras-chave: Carreira profissional; planejamento de carreira; Curso de Administração.

\section{Abstract}

The professional career is an issue that has gained increased interest from the Industrial Revolution, has gone through periods of high growth of the productive activity of the companies, suffered impacts of advances in labor relations and also of mangling the traditional model of professional success. This is a topic of interest to researchers given the different configurations that the company management has assumed over time and the transformation of economic cycles. In this scenario, this study addressed the career planning with young people in the process of completion of the university course. Their goal was to investigate the considerations that the public associates with career and how they perceive their planning. This is a qualitative, exploratory study developed with 42 graduating students of directors of a private higher education institution. Through the use of interviews, questionnaires and notes classrooms, the data were collected in two different periods (2015 and 2016). The main results of the study show that the career is a function of the conceptions that students associate with work, their life projects, and professional success. These aspects directly influence the career planning.

Keywords: Professional career; planning career; business administration.

\section{INTRODUÇão}

O mercado de trabalho tem sofrido, ao longo das últimas décadas, grandes transformações, e aquela cobiçada condição de segurança no emprego é realidade de um tempo que não existe mais, ficando restrita apenas a cargos públicos - até mesmo nessa 
esfera têm ocorrido abalos sobre essa estabilidade. Tais mudanças impactam todas as dimensões da vida de um indivíduo, e a carreira profissional pode ser comprometida.

No Brasil, percebe-se elevada taxa de desemprego entre trabalhadores mais jovens, realidade que tem sido observada desde há alguns anos (BARBOSA FILHO e MOURA2015) com tendências de continuar crescendo. Esses registros mostram também que o desemprego é maior entre jovens com baixa qualificação e poucos anos de estudo quando comparado com aqueles que detêm maior tempo e nível de escolaridade.

A conjuntura do mercado de trabalho demanda reações diversas por parte dos trabalhadores, e um recurso para aqueles que pretendem desenvolver uma atuação profissional bem-sucedida é investir em suas profissões e carreiras.

Nesse contexto, o interesse do presente artigo reside em conhecer o papel do planejamento de carreira entre jovens que estão finalizando o curso de graduação em Administração em uma instituição de ensino superior privada. Interessou-nos conhecer o sentido que eles associam ao planejamento como um recurso para gerenciar suas trajetórias de vida produtiva diante de tendências que apontam cenários econômicos altamente críticos para o ingresso e desenvolvimento em suas carreiras profissionais. Os dados foram coletados por meio de uma pesquisa qualitativa apoiada em questionário, entrevista e anotações de sala de aulas e aplicados a um grupo de estudantes em fase de conclusão do referido curso nos anos de 2015 e 2016.

Este artigo está estruturado nesta introdução, na revisão bibliográfica sobre carreira e planejamento de carreira, na descrição da metodologia, na apresentação e análise dos dados da pesquisa e nas considerações finais.

\section{REVISÃo BIBLIOGRÁFICA}

Até a década de 1980, quase nada era discutido sobre as práticas de gestão de carreiras, visto que até então era comum as pessoas deixarem que a empresa cuidasse delas até se aposentar. Essa realidade foi mudando no contexto das grandes transformações que vêm ocorrendo no contexto das relações de trabalho e também em 
função das incertezas e ambiguidades que assolam todos os campos da vida humana, nas sociedades contemporâneas.

Diante da dinâmica mutante desse cenário, o conceito de carreira profissional também mudou. No início da década de 1980, a carreira envolvia a ocorrência de transições ligadas às necessidades individuais e às imposições da organização e da sociedade; para a organização, englobariam políticas, procedimentos e decisões relacionadas à carreira na empresa (LONDON; STUMPH, 1982).

Ao final da referida década, Artur, Hall e Lawrence (1989) adotaram a definição de carreira como uma sequência de experiências profissionais, em que o trabalho influencia a maneira como os indivíduos enxergam e interagem com as outras pessoas, organizações e sociedade.

No início do século XXI, Hall (2002) identificou diferentes sentidos que a carreira tem assumido no contexto de trabalho, destacando-se:

- Carreira como avanço: tem na verticalidade o seu sentido, numa sequência de promoções e movimentos avançando sempre para cima, ou seja, para posições hierárquicas elevadas.

- Carreira como profissão: certas ocupações representam carreira, e outras, não. Nesse sentido são consideradas carreiras apenas as ocupações que mantêm um movimento progressivo de status, ao passo que as que não têm tal avanço não são consideradas como tais.

- Carreira como sequência de trabalhos durante a vida: a carreira de uma pessoa é sua história, ou a série de posições ocupadas, desconsiderando os níveis ou tipo do trabalho; nesse caso, todas as pessoas com histórias de trabalho têm carreiras.

- Carreira como a sequência de experiências relativas a funções ao longo da vida: a carreira representa a maneira como a pessoa experimenta a sequência de trabalhos e atividades que constituem sua história de trabalho.

Diante de tais variabilidades, Hall (2002, p. 44) define carreira como "a sequência individual percebida de atitudes e comportamentos associada com experiências relacionadas ao trabalho e atividades durante a vida de uma pessoa". 
Dados os diferentes sentidos e significados sociotemporais que têm sido atribuídos à carreira, Veloso e Dutra (2010) analisaram e apuraram as principais ocorrências na literatura especializada sobre o tema, cobrindo o período das décadas de 70 a 2000. O Quadro 1 apresenta uma síntese do estudo desenvolvido por estes autores.

Quadro 1: Ocorrências históricas relacionadas à carreira

\begin{tabular}{|c|c|}
\hline Década & Principais ocorrências \\
\hline 1970 & $\begin{array}{l}\text { Lançamento de três livros-chaves: Career in organizations; Career } \\
\text { dynamics; e Organizational careers. }\end{array}$ \\
\hline 1980 & $\begin{array}{l}\text { Começam a ser geradas produções acadêmicas sobre o assunto, } \\
\text { e o Handbook of Career Theory foi editado. }\end{array}$ \\
\hline \multirow{4}{*}{1990} & A obra The boundarlyless career foi editada. \\
\hline & $\begin{array}{l}\text { A discussão sobre carreira proteana ganhou mais sentido que } \\
\text { na década de } 1970 .\end{array}$ \\
\hline & $\begin{array}{l}\text { As questões que dirigiam os estudos sobre carreira passaram a } \\
\text { ter mais foco em significado do que em dinheiro; em propósito } \\
\text { que em poder; em identidade que em ego; em aprendizado que } \\
\text { em talento. }\end{array}$ \\
\hline & $\begin{array}{l}\text { Foi lançado no Brasil o primeiro livro sobre administração de } \\
\text { carreiras. }\end{array}$ \\
\hline \multirow{4}{*}{2000} & A atenção das teorias de carreira passou à perda de fronteiras. \\
\hline & $\begin{array}{l}\text { Foi lançado o livro The opt-out revolution, considerando ques- } \\
\text { tões de gênero. }\end{array}$ \\
\hline & $\begin{array}{l}\text { O Handbook of Career Studies foi organizado visando a trazer a } \\
\text { reflexão sobre múltiplos paradigmas ligados ao tema. }\end{array}$ \\
\hline & $\begin{array}{l}\text { No Brasil foi publicado o livro Gestão de carreiras e também } \\
\text { foram veiculados estudos mostrando a nova realidade na qual } \\
\text { carreira não é sinônimo de cargo. }\end{array}$ \\
\hline
\end{tabular}

Fonte: VELOSO; DUTRA (2010).

No Brasil a evolução das teorias de carreira não foi diferente do cenário econômico mundial e acompanhou as tendências globais, conforme Veloso e Dutra (2010). A seguir mostra-se uma síntese apurada por esses autores, cobrindo o período compreendido entre 1970 a 2000. 
- Nos anos 70 - marcada pela ditadura militar e repressão aos sindicatos; crescimento econômico acelerado e baixa qualificação da mão de obra, e havia foco no treinamento e controle das pessoas pessoas; a carreira podia ser vista como vida na empresa.

- Nos anos 80 - década marcada pela estagnação da economia, hiperinflação e retração da produção industrial, planos econômicos e demissões; a carreira na empresa podia ser vista como uma árvore ou sequência de cargos.

- Nos anos 90 - avanço tecnológico, desemprego, abertura dos mercados e crise no sindicalismo foram as marcas dessa década. A gestão de pessoas passou a conviver com termos tais como downsizing, reengenharia, terceirização, contratos com pessoas jurídicas e cargos compactados e remuneração variável; a carreira passou a ser representada por novas possibilidades de empregabilidade.

- Nos anos 2000 - década marcada pela globalização. Conceitos como responsabilidade social e ambiental estavam juntos com a sustentabilidade. Época de grandes fusões e aquisições. Começou-se a discutir governança corporativa, remuneração baseada em competências, gestão participativa e alinhamento entre vida pessoal e profissional; as carreiras se tornaram sem fronteiras.

\section{Planejamento da CARReira PRofissional}

O contexto de elevada competição no mercado de trabalho tem sinalizado para a necessidade de os profissionais dedicarem atenção à gestão de suas carreiras - o que implica projetar e gerenciar o seu planejamento, manutenção e/ou redirecionamento. Essa demanda se mostra de igual importância para jovens recém-ingressos ou em fase de preparo para se inserirem no mundo do trabalho. Embora a gestão da carreira não seja uma medida de garantia de emprego, ela se torna um valioso recurso para promover reflexões sobre um conjunto de questões e problemas que podem ser discutidos durante o período da graduação, tanto quanto para se obter melhor compreensão sobre o mecanismo que tece uma trajetória profissional. 
Para Brasil et al. (2012), quando o estudante se "deparar consigo mesmo", poderá avaliar melhor suas qualificações e suas características positivas e limitantes e identificar aspectos que precisam ser melhorados. Pode ainda repensar o contexto de trabalho do país e projetar cenários, sempre tentando alinhar sua vida acadêmica com as necessidades do mercado de trabalho.

É nesse contexto que o planejamento de carreira surge, tentando responder a uma diversidade de assuntos que envolve, dentre outros, o autoconhecimento e competências como determinação, disciplina, discernimento e visão sistêmica, além de compreensão sobre reflexos da situação econômica do país, mercado de trabalho e suas tendências e a criação de novas ocupações (muito em função dos avanços da internet e novas tecnologias) (DUTRA, 1996).

Lopes (2004) entende que planejar uma carreira é criar um mapa geográfico no qual se mostram os destinos e os trajetos a serem percorridos para alcançá-los.

Trata-se, segundo Dutra (1996), de um processo complexo, pois implica prospectar ações presentes para dar sustentação e orientarão aos caminhos que levarão aos objetivos pretendidos. Nesse processo, o profissional deve partir da avaliação de seus valores, competências, potencialidades para que possa analisar as oportunidades que irão surgir aliadas com os recursos e caminhos possíveis para que então atingir os objetivos almejados.

De acordo com Brasil et al. (2012), o planejamento da carreira, ainda na fase de formação acadêmica, permitirá ao estudante da graduação proceder reflexões sobre uma variedade de questões. Estas lhe possibilitam adotar mudanças de rota ou ajustes na sua formação acadêmica, de maneira a colocar metas e objetivos bem definidos e condizentes com suas expectativas e valores pessoais, podendo também criar estratégias de como alcançá-los.

Boa parte dos estudantes passam a se preocupar com o ingresso no mercado de trabalho apenas por ocasião da finalização do curso e esbarram em situações adversas que os levam a sentir desestimulados a seguir em frente, podendo até mesmo desistir da profissão em que se formaram. Esse é um dos motivos pelos quais um grande número de pessoas está trabalhando fora de suas áreas de formação, 
pois sem planejamento têm muitas dificuldades para encontrar um emprego e se desenvolverem profissionalmente.

Registra-se que nesse contexto o planejamento de carreira tem um papel fundamental da vida acadêmica dos estudantes de graduação (BRASIL et al., 2012).

Pensando na carreira como um processo de construção, Lemos, Cavazotte e Viana (2012) realizaram uma pesquisa na qual foram entrevistados 32 alunos de graduação em Administração de duas universidades privadas do Rio de Janeiro nos anos de 2009 e 2010. A finalidade era entender as expectativas deles os e valores relativos ao trabalho nas organizações depois de formados.

Os autores buscaram retratar os jovens contemporâneos buscando compreender a essência dos seus valores e suas escolhas, para analisar como eles veem o mundo do trabalho e suas motivações no planejamento de suas carreiras. Uma das motivações mais citadas nos relatos dos entrevistados foi a "realização". Palavras como ambição, sucesso, capacidade e influência ficaram muito evidenciadas nas falas dos alunos, mostrando que apreciam o sucesso e a realização tanto pessoal como profissional.

Outra característica foi o surgimento da necessidade de verem seu trabalho valorizado e reconhecido, visando a oportunidades de crescimento, o que deu tornou possível concluir que os jovens entrevistados são muito ambiciosos. O desejo de poder foi outro fator motivacional surgido na pesquisa, apesar de menos enfatizado que a "realização".

Ficou evidenciado no estudo por palavras como riqueza, reconhecimento e influência, e ainda que a remuneração não tenha sido tratada como prioridade para muitos dos entrevistados, ela apareceu com ênfase em muitos deles como um dos fatores de muita importância. Isso mostrou que a demanda pelo poder vinha do acesso ao dinheiro para dar vazão aos prazeres materiais, como comprar roupas, comer em bons restaurantes, viagens e novidades de consumo (LEMOS; CAVAZOTTE; VIANA, 2012).

A expectativa de ganhar um bom salário também surgiu como um elemento motivador, mostrando que a recompensa tem grande impacto no planejamento da carreira. Esse fator não pode deixar 
de ser levado em consideração pelas empresas que desejam atrair e reter talentos.

Finalmente os autores da pesquisa mostram o hedonismo - geralmente associado a um autoaperfeiçoamento - como uma motivação importante para entender as expectativas dos alunos entrevistados, consoante a literatura que mostra os jovens contemporâneos focados em prazer e satisfação pessoal (ALSOP, 2008; SMOLA; SUTTON, 2002). Ao responderem a entrevista, associaram prazer e trabalho, se referindo a condições de trabalhos futuras, evidenciando uma preocupação em equilibrar a vida pessoal com a profissional.

\section{METOdOLOGIA Do ESTUdo}

A pesquisa realizada foi do tipo qualitativa descritiva (SAMPIERE; COLLADO; LUCIO, 2013), e teve como objetivo investigar o planejamento da carreira entre um grupo de estudantes concluintes do curso de Administração de uma instituição de ensino superior privada.

O processo de coleta de dados se deu em duas fases: a primeira ocorreu no 6⿳⺈ período do curso (segundo semestre de 2015), durante a disciplina Carreira Profissional - escolhida pelos estudantes na modalidade eletiva e ministrada por um dos autores deste artigo; e a segunda aconteceu no $8^{o}$ período (primeiro semestre de 2016) da mesma turma de estudantes.

Em ambas as fases, o estudo procurou investigar temas relacionados à formação obtida durante o curso como ingresso no mercado de trabalho, atuação profissional, pretensões e propostas de carreira; na segunda fase, o enfoque maior recaiu sobre planejamento da carreira.

Desse modo, a pesquisa aqui apresentada traz, em sua maior parte, os dados da segunda fase, mas também recorreu aos da fase anterior para estabelecer vínculos com informações já elaboradas, possibilitando também a construção de sentidos e significados (GODOI; BANDEIRA-DE-MELLO; SILVA, 2010; CRESWELL, 2014). Na primeira fase participaram 44 estudantes que compõem a turma e, na segunda, 42; isso significa que o mesmo público está presente nos 
dois períodos investigados, exceto dois estudantes que deixaram o curso entre um ano e outro.

Na primeira fase da pesquisa, que ocorreu ao longo de um semestre letivo, foram utilizados dois questionários, entrevistas presenciais, registros de sala de aulas e observação participante. $\mathrm{Na}$ segunda fase, utilizou-se um questionário padrão o qual foi aplicado aos estudantes na penúltima semana do curso. Esse instrumento versou sobre questões específicas relacionadas ao conceito de carreira que os estudantes apreenderam ao longo da sua formação; o valor que associam ao planejamento de carreira; a existência de um plano de carreira próprio; justificativas para adotar ou não esse plano de carreira; e conceito de sucesso profissional.

Os questionários foram analisados pelo aplicativo SPSS, e a construção dos significados e sentidos ocorreu pela articulação dos resultados obtidos nas duas fases, conforme já comentado.

\section{RESULTADOS E ANÁLISE}

A seguir apresentam-se os principais resultados do estudo em dois blocos: perfil dos estudantes e considerações sobre plano de carreira.

\section{Perfil sociodemográfico, acadêmico e profissional dos estu- dantes}

Esse perfil foi construído a partir dos dados coletados na segunda fase representando a realidade demográfica, acadêmica e profissional atual dos estudantes.

A idade do grupo participante da pesquisa variou entre 19 e 28 anos, e a maioria $(55,76 \%)$ tem idade entre 22 e 24 anos. O gênero feminino predominou entre $56,32 \%$ deles. Cerca de $72 \%$ dos estudantes residem com os pais, os demais (28\%) estão distribuídos em pensionato, república de estudante, residências de amigos e com o cônjuge.

Quanto à renda mensal dos estudantes que estavam trabalhando na época da pesquisa $(95,24 \%)$, observou-se variação de valores entre $\mathrm{R} \$ 1.500,00$ a $\mathrm{R} \$ 5.000,00 ; 73 \%$ tem salário de até $\mathrm{R} \$ 2.000,00$; entre os demais $(27 \%)$, apenas $2,38 \%$ recebem salário no valor máximo da faixa identificada. 
O grupo de estudantes ingressou no curso no ano de 2013, e $79,38 \%$ é concluinte em 2016; os demais se encontram com pendências acadêmicas (disciplina e estágio) e planejam concluir o curso no primeiro semestre de 2017.

Quanto ao momento em que ingressaram no mercado de trabalho observou-se que no caso de $40 \%$ deles isso ocorreu com a idade de 18 anos; para 28\%, entre os 15 e 17 anos; e para os demais, a partir dos 19 anos.

Quanto ao campo de atuação profissional, cerca de 96\% trabalham em ocupações atinentes à formação em Administração de Empresas, e 4\% atuam fora da área como corretor de imóvel e vendedor de carros; eles alegaram que pretendem mudar para a área de formação.

Dentre o grupo de estudantes, $62 \%$ trabalham com vínculos empregatícios em empresas privadas, 21,43\% têm negócio próprio ou da família, e os demais (16,63\%) são autônomos.

\section{Sobre planejamento da carreira}

As questões que investigaram o planejamento de carreira foram estruturadas a partir de uma pergunta-chave: você tem um plano de carreira? A resposta conduziu o desdobramento das questões subsequentes organizadas para investigar as percepções dos dois tipos de respostas: sim e não. Os comentários decorrentes foram elaborados pela articulação dos dados coletados tanto na pesquisa atual (2016) quanto na realizada em 2015.

Quanto à existência de plano de carreira - Entre os estudantes, $27,14 \%$ responderam "não" para ter plano de carreira, os demais $(72,86 \%)$ afirmaram tê-lo.

Justificativa dos estudantes que têm o plano de carreira quanto às justificativas sobre ter um plano de carreira $37,78 \%$ responderam que esse instrumento "me fornece informações para eu desenvolver processos de aprendizagem na pós-graduação"; para "continuar me capacitando em outros cursos"; e para "manter-me atualizado". Para 25,08\% dos estudantes, o plano de carreira "ajuda a ter uma visão mais clara do que quero atingir na vida profissional"; os demais (20,0\%) justificaram "o plano é um instrumento que me transporta para os meus 
objetivos"; é um "recurso para poder mudar a carreira"; e "seu acompanhamento me disciplina quando tenho que fazer mudanças de trajeto".

Justificativa para não ter o plano de carreira - observou-se que dos $27,14 \%$ dos estudantes (que não possuem um plano de carreira) as justificativas para não tê-lo variaram entre os argumentos: " $a$ carreira se constrói com o tempo e não é possível planejá-la"; "as oportunidades de trabalho podem aparecer sem a existência de um plano"; "o plano engessa a mobilidade"; e "não sabe elaborar esse plano".

Elaboração do plano de carreira - ao serem indagados sobre a elaboração do plano de carreira, as respostas dos que tem o referido plano variaram entre as seguintes afirmações "fiz durante as aulas da disciplina Carreira Profissional" (31\%); "contei com a ajuda de profissionais da família" (6\%); "a empresa onde trabalho montou comigo o plano" (28,86\%); e "contratei assessoria externa" (7\%).

Aspectos do plano de carreira que mais valorizam - entre os elementos que podem compor um plano de carreira (desenvolvimento humano e profissional, processos de aprendizagem, relacionamentos sociais e familiares, ocupações de cargos, posições de status, ganhos financeiros, liderança, empreendedorismo, experiências e vivências, definição de tempo e metas e outros), os aspectos mais valorizados pelos estudantes (que têm o plano) estão resumidos nas expressões:

"o plano é oportuno para eu fazer um exercício de autoconhecimento" "a partir dele fico conhecendo melhor meus pontos positivos e negativos" "o plano envolve reflexões sobre vários aspectos da vida como a família e não apenas sobre mim"

"através dele eu posso definir melhor as condições que preciso para ampliar e diversificar contatos e relacionamentos"

"o plano me ajuda a buscar elevados níveis de qualidade de vida" "com ele posso projetar experiência internacional; "planejar viagens para capacitação"

"viabilizará eu conhecer novos tipos de trabalhos"

"projeto através do plano conviver com diferentes culturas e valores" "ele me ajudou a organizar melhor os diferentes papéis que temos na vida"

\footnotetext{
"serve para determinar o tempo das coisas quero realizar na vida".
} 
Os aspectos menos apontados foram:

"atingir posição elevada na hierarquia organizacional"

"garantir maior estabilidade no trabalho"

"alcançar um nível salarial elevado"

"estar tecnicamente preparado para o mercado de trabalho"

"aumentar capacidade para concorrer a vagas de emprego".

Sucesso profissional e sua relação com o plano de carreira o conceito de sucesso profissional apresentado pelos estudantes se relaciona a diferentes sentidos e significados que eles associam à vida profissional. Observou-se que para 27,14\% deles (os que não possuem um plano de carreira), o conceito de sucesso resumiu-se às seguintes definiçõos:

"capacidade de alguém se realizar como pessoa e como profissional"

"sair bem na área de formação acadêmica"

"fazer aquilo que realmente gosta"

"trabalhar pouco e viver bem"

"ser reconhecido e respeitado pelo que faz".

Em relação aos estudantes que têm plano de carreira, as definições mais frequentes para sucesso profissional apontaram as seguintes definições:

"atingir autoconhecimento e autorrealização pessoal"

"estar atuando onde gostaria de trabalhar"

"sentir que o trabalho e a vida é uma coisa só"

"se realizar como trabalhador e como pessoa"

"ter versatilidade para mudar de emprego ou até de profissão"

"poder estar bem com a família, amigos"

"conciliar emprego e lazer"

"estar sempre conhecendo, crescendo e inovando"

"não fazer a mesma coisa por muito tempo".

Quando indagados sobre a relação entre sucesso profissional e planejamento de carreira, houve a seguinte resposta para estudantes com plano de carreira: 
“o plano é uma forma de projetar no dia de hoje aquilo que me fará feliz na vida profissional"

"se sei o que quero da vida profissional por que não escrever isso no papel e cumprir?"

"encaro o plano como uma promessa, um compromisso com o meu sucesso profissional"

"penso que a relação está entre ser coerente com o que se planeja... tem que cuidar para fazer as mudanças no plano... não é algo estático... mas deve ser respeitado"

"eu vou estudar maquiagem cinematográfica na Califórnia. Isso está no meu plano para o ano de 2017 [...] lembro disso toda semana... está registrado e assim nada me tira deste foco"

"o plano passou a ser um compromisso familiar... meu pai está sempre vendo ele comigo e todos da minha família me apoiam na sua realização"

"sem o plano e sem cumprir as metas dele eu não chego onde quero na empresa da família...vou ser o próximo sucessor e quero ter muito sucesso porque meu pai foi um grande gestor".

Os estudantes sem plano de carreira consideram que ele não tem muita ligação com o sucesso profissional. Consideram que o sucesso:

"vai depender muito mais das condições que estiverem presentes tanto no cenário econômico (de modo geral)..., nas condições financeiras da empresa que estiver trabalhando, no tipo de ambiente de trabalho, da liderança e das pessoas com quem vou trabalhar" "se eu estiver fazendo o que gosto, está tudo bem e serei vencedor" "eu não preciso do plano para ser bem-sucedido profissionalmente, preciso de muito preparo e sorte".

\section{ANÁlise E CONSIDERAÇõeS FINAIS}

O planejamento da carreira recebeu visão diferenciada entre os estudantes pesquisados. Todavia, a pesquisa mostrou que para a maioria deles (grupo que tem o referido plano) trata-se de um recurso valioso, principalmente na fase em que se encontram em relação ao mercado de trabalho e às suas pretensões profissionais. 
Ao associarmos as respostas dos estudantes para as questões que envolvem o plano de carreira observamos estreita ligação com os tipos de carreira que pretendem desenvolver. Na tipologia apresentada por Hall (1996) destaca-se o tipo proteano, justificado pelas seguintes razões:

a) o grupo de estudantes com plano de carreira tem o entendimento de que a carreira profissional, na atualidade, é assunto que merece gestão e como tal está sujeita a monitoramentos, revisões, mudanças, reprogramações e adaptações constantes;

b) a carreira é algo mais amplo do que galgar posições na hierarquia organizacional, pois ela estabelece relações com outros aspectos emocionais e sociais da vida como família, amigos, papéis que irão desenvolver ao longo da existência. Sendo assim, a escalada vertical ou as paradas nos degraus hierárquicos (carreira do tipo tradicional) podem comprometer o desenvolvimento de tais papéis, daí o sentido holístico (OSWALDO, 2015) que tem sido associado a carreira; ou seja, ela se liga a várias dimensões da vida humana e não mais e apenas ao universo do local de trabalho ou da ocupação da pessoa;

c) a carreira se mostra como uma oportunidade para o autodesenvolvimento, confirmando assim a pesquisa de Lemos, Cavazotte e Viana (2012). Nessa perspectiva, o planejamento da carreira é um momento de se pensar qual relação profissional se pretende desenvolver com o trabalho para atender quais valores de vida e não simplesmente para se ter ocupação durante o período de atividade produtiva;

d) nessa linha o plano da carreira é concebido não apenas em função de pretensões de ganhos econômicos mas, sobretudo, como uma condição de ganhos de qualidade de vida e de trabalho dotado de sentido e significado para si e para o seu rol de relacionamentos;

e) o plano da carreira passa a ser entendido como um propósito de vida porque nele não se registram apenas as pretensões de natureza laboral, mas também se incluem 
os diferentes aspectos que dão sustentação e direção à vivência humana como lazer, oportunidades de conhecer novas culturas, experienciar novos vínculos de trabalho, autorrealização e prazer ampliado para outros grupos de proximidade como a família e amigos.

Desse modo, o plano de carreira assume a forma de um contrato psicológico com a vida profissional do qual não ficam de fora as questões relacionadas ao bem viver e à autorrealização. Nesse contexto, o estudante se coloca como protagonista da sua vida, e o sucesso se torna um fenômeno psicologicamente interiorizado.

Para os estudantes que não têm plano de carreira denota-se a crença de que vida e trabalho são dimensões separadas e que a carreira é fruto de eventos externos. Nesse caso, planejá-la não é possível dada a impossibilidade de captar os aspectos da sazonalidade e imprevisibilidade dos cenários econômicos e do mercado de trabalho, bem como o engessamento que esse plano irá gerar. Nesse contexto, o estudante se coloca como coadjuvante da sua vida profissional, e o sucesso é definido pela ação e pelos impactos das externalidades.

Os novos tipos de carreira que estão surgindo mostram-se mais alinhados com os aspectos de realização do indivíduo e menos voltados para o atendimento das necessidades das empresas. Isso porque elas vêm se descomprometendo, cada vez mais, com o oferecimento de políticas de carreiras, tanto quanto investindo no desenvolvimento de um grupo reduzido de profissionais - o suficiente para manter seus cargos-chaves em operação.

De fato, a carreira profissional difere da carreira organizacional: a primeira é projetada para fora da organização, ao passo que a segunda é voltada para dentro dela. Isso parece estar ficando claro para os estudantes do curso de Administração, principalmente para os que se encontram em fase de ingresso no mercado de trabalho ou recém-contratados.

O estudo gerou pressupostos para a sua continuidade, dentre eles, destacam-se dois: a) a carreira profissional é função das concepções que o jovem tem sobre trabalho e vida, e o seu planejamento sofre os impactos do conceito de sucesso que eles projetam 
alcançar; e b) o sucesso profissional se amplia para outras regiões da vivência humana e inclui aspectos pessoais, familiares, sociais, culturais e laborais.

\section{REFERÊNCIAS}

BARBOSA FILHO, F.H.; MOURA, R. L. Evolução recente da informalidade do emprego no Brasil: Uma análise segundo as características da oferta do trabalho e o setor. Pesquisa e planejamento ecômico, vol. 45, n. 1, abr/2015.

ALSOP, R. The Tropy Kids Grow Up: How the millennial generation is shaking up the workplace. EUA: Jossey-Bass, 2008.

ARTHUR, M. B., HALL, D. T., \& LAWRENCE, B. S. (Orgs.). Handbook of career theory. New York: Cambridge University Press, 1989.

BRASIL, V. et al. Orientação profissional e planejamento de carreira para universitários. Cadernos Acadêmicos, Palhoça, v. 4, n. 1, p. 117-131, fev./jul. 2012.

CRESWELL, W. J. Investigação qualitativa e projeto de pesquisa. 3. ed. Porto Alegre: Penso, 2014.

DUTRA, J. S. Administração de carreiras: uma proposta para repensar a gestão de pessoas. São Paulo: Atlas, 1996.

GODOI, K. C.; BANDEIRA-DE-MELLO, R.; DA SILVA, B. A. Pesquisa qualitativa em estudos organizacionais: paradigmas, estratégias e métodos. 2. ed. São Paulo: Saraiva, 2010.

HALL, D. T. Protean carrers of the $21^{\text {st }}$ century. Academy of Management Executive, v. 10, n. 4, p. 8-16, 1996.

HALL, D. T. Careers in and out of organizations. London: Sage, 2002.

LEMOS, A. H. C; CAVAZOTTE, F. S. C. N.; VIANA, M. D. A. Os jovens e o trabalho: Valores, escolhas e expectativas. Juventudes e gerações no Brasil contemporâneo. Porto Alegre: Sulina, 2012.

LONDON, M.; STUMPH, S. (1982). Managing careers. Reading, MA: Addison-Wesley.

LOPES, M. Gestão e planejamento de carreira. 2004. Disponível em:

<http://moyseslopes.blogspot.com/2008/06/gesto-e-planejamento-de-carreira-para.html>.

Acesso em: 1 ago. 2016

OSWALDO, Y. C. Planejamento estratégico e autogestão de carreira. 3a edição. São Paulo: Life Editora, 2015.

SAMPIERE, H. R.; COLLADO, F. C.; LUCIO, B. P. DEL M. Metodologia de pesquisa. 5. ed. Porto Alegre: Penso, 2013.

SMOLA, K. W.; SUTTON, C. D. Generational Differences: revisiting generational work values for the new millenium. Journal of Organizational Behavior, v. 23, p. 363-382, 2002. Published online in Wiley InterScience (www.interscience.wiley.com). DOI: 10.1002/job.147 
VELOSO, E. F. R.; DUTRA, J. S. Evolução do conceito de carreira e sua aplicação para a organização e para as pessoas. In: DUTRA, J. S. (Org.). Gestão de carreiras na empresa contemporânea. São Paulo: Atlas, 2010, v. 1, p. 3-39.

Recebido em: 4-8-2016

Aprovado em: 2-5-2017

Avaliado pelo sistema double blind review.

Editor: Elmo Tambosi Filho

Disponível em http://mjs.metodista.br/index.php/roc 